\title{
Uncatalyzed thermal gas phase aziridination of alkenes by organic azides. Part I: Mechanisms with discrete nitrene species
}

\author{
S PREMILA DEVI, TEJESHWORI SALAM and R H DUNCAN LYNGDOH* \\ Department of Chemistry, North-Eastern Hill University, Shillong 793 022, India \\ e-mail: rhdl@nehu.ac.in
}

MS received 28 September 2015; revised 8 February 2016; accepted 2 March 2016

\begin{abstract}
Alkene aziridination by azides through uncatalyzed thermal gas phase routes has been studied using the DFT B3LYP/6-31G(d,p) method, where the possible role of discrete nitrene intermediates is emphasized. The thermal decomposition of azides is studied using the MP2/aug-cc-pVDZ strategy as well. The MP2 (but not the B3LYP) results discount the existence of singlet alkylnitrenes where the alkyl group has an $\alpha$ hydrogen. Addition of the lowest lying singlet and triplet nitrenes $\mathrm{R}-\mathrm{N}(\mathrm{R}=\mathrm{H}, \mathrm{Me}, \mathrm{Ac})$ to four different alkene substrates leading to aziridine formation was studied by the B3LYP method. Singlet nitrenes with alkenes can yield aziridines via a concerted mechanism, where $\mathrm{H}-\mathrm{N}$ insertion takes place without a barrier, whereas Me-N shows larger barriers than Ac-N. Methyl substitution in the alkene favors this reaction. Triplet nitrene addition to alkenes is studied as a two-step process, where the initially formed diradical intermediates cyclize to form aziridines by ISC (intersystem crossing) and collapse. Scope for C-C bond rotation in the diradical leads to loss of stereochemical integrity for triplet nitrene addition to cis- and trans-2-butenes. Geometries of the transition states in the various reaction steps studied here are described as "early" or "late" in good accordance with the Hammond postulate.
\end{abstract}

Keywords. Alkene aziridination; azide decomposition; singlet and triplet nitrenes; density functional theory.

\section{Introduction}

First proposed as intermediates in 1891, nitrenes figure in many reviews and monographs. ${ }^{1-6}$ They exist as discrete species, or as moieties transferred without free existence. Aziridines may be formed by catalyzed or uncatalyzed nitrene transfer to alkenes. Nitrene sources include azides, ${ }^{7}$ sulfonamides ${ }^{8}$ chloramine-T and bromamine-T, ${ }^{9-12}$ alkyl tin azides ${ }^{13}$ and hypervalent iodine compounds like $\mathrm{PhI}=\mathrm{NTs} .{ }^{14-16}$ Substrates include cyclic and acyclic alkenes as well as fullerenes. ${ }^{17-20}$ This computational study focuses on aziridination of alkenes by azides $\left(\mathbf{R N}_{3}\right)$ via thermal, uncatalyzed gas phase mechanisms involving formation of free singlet and triplet nitrenes (R-N) derived from the decomposition of azides. Reactions without free nitrenes are not treated here, neither are the mechanisms under photochemical, catalyzed or solvated conditions, although these are important for aziridine synthesis. ${ }^{3-6,21-28}$

\subsection{Thermal Decomposition of Organic Azides}

The two alkene aziridination mechanisms studied here begin with thermal decomposition of azides. Azide

\footnotetext{
*For correspondence
}

decomposition may result in insertion of nitrene moieties into $\mathrm{C}=\mathrm{C}$ double bonds or $\mathrm{C}-\mathrm{H}$ single bonds. ${ }^{21,22}$

Thermal decomposition of $\mathrm{HN}_{3}$ yielded $\mathrm{N}_{2}, \mathrm{NH}_{3}$, polymers and aziridine with ethene. ${ }^{29}$ Thermal decomposition of $\mathrm{HN}_{3}$ in $\mathrm{Ar}$ at high temperatures produced singlet and triplet $\mathrm{NH}^{30}$ Pyrolysis of $\mathrm{MeN}_{3}$ resulted in $\mathrm{N}_{2}, \mathrm{H}_{2}$ and $\mathrm{HCN}$ as products. ${ }^{31}$ Thermal decomposition of gaseous $\mathrm{MeN}_{3}$ gave triplet $\mathrm{MeN}$ and $\mathrm{N}_{2}$, and polymers with alkenes. ${ }^{32}$ The thermal Curtius rearrangement of acyl azides involves alkyl group shift without yielding free acylnitrenes.

The thermal decomposition of azides has been well studied by computational methods. ${ }^{33-39}$ A QCISD(T)// UMP2/6-31G(d,p) study ${ }^{34}$ on thermal decomposition of $\mathrm{MeN}_{3}$ predicted it decomposes concertedly to $\mathrm{CH}_{2}=$ $\mathrm{NH}$ and $\mathrm{N}_{2}$, while triplet $\mathrm{MeN}_{3}$ collapses to triplet MeN plus $\mathrm{N}_{2}$. A CAS study with an MP2 zeroth order wavefunction ${ }^{35}$ predicted the adiabatic step $\mathrm{CH}_{3} \mathrm{~N}_{3} \rightarrow$ $\mathrm{CH}_{3} \mathrm{~N}+\mathrm{N}_{2}$ with spin-allowed and spin-forbidden routes, both of similar energies. DFT, MP2 and MP4 studies ${ }^{36}$ on thermal decomposition of $\mathrm{MeN}_{3}$ and $\mathrm{EtN}_{3}$ led to computation of activation energies and preexponential factors. CASSCF studies $^{37}$ on thermal decomposition of $\mathrm{EtN}_{3}$ located routes for generation of singlet and triplet EtN with rearrangement to ethanimine. CASPT2//CASSCF studies on $\mathrm{N}_{2}$ extrusion from $\mathrm{HN}_{3}, \mathrm{MeN}_{3}$ and $\mathrm{EtN}_{3}$ predicted spin-allowed and 
spin-forbidden channels with similar barriers to give singlet and triplet nitrenes. ${ }^{38}$ An (MP2)(full)/6-31G* study $^{39}$ on thermal decomposition of acyl azides predicted a one-step route for formyl azide, and two-step routes for acetyl and benzoyl azides, both leading to formation of isocyanate and $\mathrm{N}_{2}$. A recent study on the Curtius rearrangement of $\mathrm{ClF}_{2} \mathrm{C}-\mathrm{CO}-\mathrm{N}_{3}$ predicted a concerted pathway as preferred pathway over a stepwise pathway for the isocyanate formation. ${ }^{40} \mathrm{~A}$ theoretical atoms-in-molecules study showed the decomposition of vinyl azide to ketenimine to be concerted, while that to acetonitrile is stepwise; singlet and triplet vinyl nitrenes were also identified as minima. ${ }^{41}$

\subsection{Singlet and Triplet Nitrenes as Discrete Species}

The two mechanisms for alkene aziridination studied here involve the free (discrete) singlet and triplet nitrene species respectively. Singlet nitrenes are expected to insert in a concerted, stereospecific manner. Pentafluorophenylnitrene was shown to insert into alkenes ${ }^{42}$ yielding aziridines without 1,3-dipolar cycloaddition between precursor and alkene. Sulfonylnitrene generated from $\mathrm{N}, \mathrm{N}$-dibromo- $p$-toluenesulfonamide was found to add to alkenes forming aziridines. ${ }^{43}$ The free existence of nitrene in the thermal Curtius rearrangement of benzoyl and pivaloyl azides was ruled out. ${ }^{44,45}$ However, the free existence of vinylnitrenes and of cyanonitrene is inferred from experimental studies. ${ }^{46,47}$ Decomposition of ethyl azidoformate in 4-methyl-2pentenes led to the stereospecific formation of aziridines. $^{48}$ Carbethoxynitrene inserts stereospecifically into tertiary $\mathrm{C}-\mathrm{H}$ bonds and adds to alkenes giving aziridines. ${ }^{49}$

Triplet nitrene addition to alkenes is non-stereospecific. Triplet NH adds to alkenes via an intermediate triplet diradical adduct. ${ }^{50}$ Singlet and triplet carbethoxynitrene from photolysis of ethyl azidoformate ${ }^{51}$ or by $\alpha$-elimination ${ }^{49}$ can insert into $\mathrm{C}-\mathrm{H}$ and $\mathrm{C}=\mathrm{C}$ bonds. Triplet[(trifluoromethyl)(sulfonyl)]nitrene was obtained photochemically in a low temperature matrix and characterized by IR and EPR spectroscopy. ${ }^{52}$
Extensive computational studies have been carried out on discrete nitrenes. ${ }^{53}$ The MRD CI method was used $^{54}$ to study addition of singlet and triplet $\mathrm{NH}$ to ethene, earlier studied for the triplet species using $a b$ initio SCF theory. ${ }^{55}$ Low lying singlet and triplet states of MeN were studied by ab initio SCF theory.$^{56} \mathrm{Ab}$ initio $\mathrm{SCF}$ theory predicted triplet $\mathrm{MeN}$ isomerization to $\mathrm{CH}_{2}=\mathrm{NH}$ would involve a large barrier, pointing to the stability of triplet $\mathrm{MeN}$ in absence of collisions. ${ }^{57}$ SCF and CISD methods with large basis sets were utilized to study the rearrangement of singlet $\mathrm{CH}_{3} \mathrm{~N}$ to $\mathrm{CH}_{2}=\mathrm{NH}$, which occurs without a barrier. ${ }^{58} \mathrm{CASSCF}$ and CASPT2 results, however, predicted singlet MeN as a minimumwhich rearranges through tunneling. ${ }^{59} \mathrm{An}$ SCF-MO study ${ }^{60}$ assigned triplet ground states to alkanoylnitrenes $\mathrm{RC}(\mathrm{O}) \mathrm{N}$ and singlet ground states to carbalkoxynitrenes ROC(O)N. CCSD(T) and G2 studies ${ }^{61}$ on singlet-triplet gaps for carbonylnitrenes predicted a singlet ground state for benzoylnitrene, which is experimentally proven through photolysis of benzoyl azide. DFT and CBS-QB3 studies predict rather small barriers for acetylnitrene addition to ethene. ${ }^{62}$

\subsection{Aziridination Mechanisms}

This study focuses on three azides $\mathbf{R}-\mathrm{N}_{3}$ as nitrene sources $(\mathbf{R}=\mathrm{H}, \mathrm{Me}, \mathrm{Ac})$ and four alkenes (ethene, propene, cis- and trans-2-butene) shown in figure 1. The first aziridination mechanism studied here involves singlet nitrenes, and the second involves the triplet nitrene. Both mechanisms are treated here as thermal, gas phase and uncatalyzed reactions.

The first mechanism for aziridination has two concerted steps - singlet nitrene generation by thermal decomposition of the azide, followed by nitrene addition to alkene. Figure 2 a depicts pyrolysis of singlet ground state azide $\mathbf{R}-\mathrm{N}_{3}$ to give singlet nitrene R-N plus $\mathrm{N}_{2}$ via transition state TS1. Singlet nitrene generation from azide may compete with rearrangements, including 1,2 hydride shifts in alkyl azides having an alkyl group $\alpha$-hydrogen to form an imine and $\mathrm{N}_{2}$ via transition state TS2 (figure $2 b$ ).

$$
\begin{aligned}
& \mathrm{H}-\mathrm{N}=\stackrel{\oplus}{\mathrm{N}}=\stackrel{\ominus}{\mathrm{N}} \\
& \text { hydrazoic acid } \\
& \mathrm{H}_{2} \mathrm{C}=\mathrm{CH}_{2} \\
& \text { ethene }
\end{aligned}
$$$$
\mathrm{H}_{3} \mathrm{C}-\mathrm{N}=\stackrel{\oplus}{\mathrm{N}}=\stackrel{\ominus}{\mathrm{N}}
$$$$
\text { methyl azide }
$$<smiles>C/C=C\O</smiles><smiles>CC(=O)N=[N+]=[N-]</smiles>
acetyl azide<smiles>C/C=C\C</smiles>

Figure 1. Organic azides as nitrene transfer agents and alkenes as substrates for the aziridination reaction. 
In the second step of the first mechanism shown in figure $2 c$, the singlet nitrene adds to the alkene $\mathrm{C}=\mathrm{C}$ double bond via transition state TS3 before undergoing spin inversion to triplet nitrene. Propene has two orientations for nitrene addition, with the nitrene $\mathbf{R}$ group pointing away from or towards the propene methyl group (the A and B options).

The second mechanism for alkene aziridination involves step-wise addition of triplet nitrene to the alkene $\mathrm{C}=\mathrm{C}$ bond of a cis alkene via transition state TS4 (figure 3). The triplet nitrene may arise from the singlet azide via the intersystem crossing (ISC) intersection point indicated by some studies ${ }^{35-38}$ or else by ISC immediately after the singlet nitrene is generated by adiabatic thermal decomposition of the azide. Triplet nitrene addition to alkene leads to the formation of a triplet diradical intermediate (conformer A) via transition state TS4. The triplet diradical conformer A is found to further undergo $\mathrm{C}-\mathrm{C}$ bond rotation to give conformer $\mathbf{B}$, thereby allowing the formation of both cis and trans aziridines from either cis or trans alkene. The triplet diradical may undergo ISC to give the singlet diradical (if it exists at all). We suggest that the singlet diradicals do not exist as minima, but collapse to

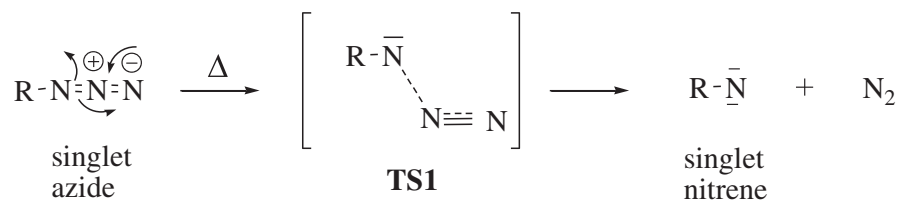

(a)

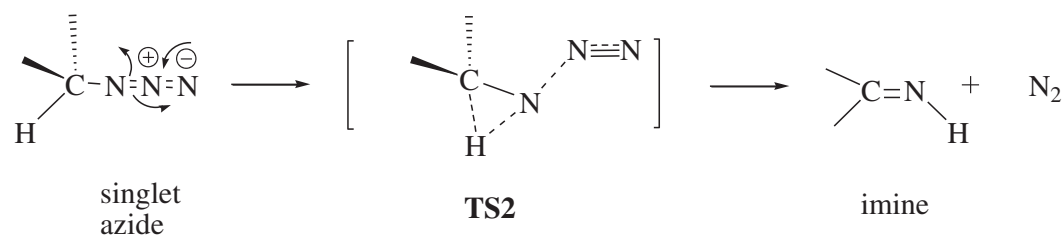

(b)

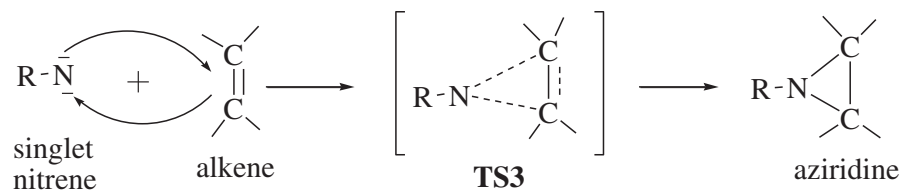

(c)

Figure 2. Mechanisms for (a) thermal decomposition of azide to singlet nitrene and $\mathrm{N}_{2}$, (b) azide decomposition to imine and $\mathrm{N}_{2}$ by 1,2 hydride shift, and (c) concerted addition of singlet nitrene to alkene forming aziridine.
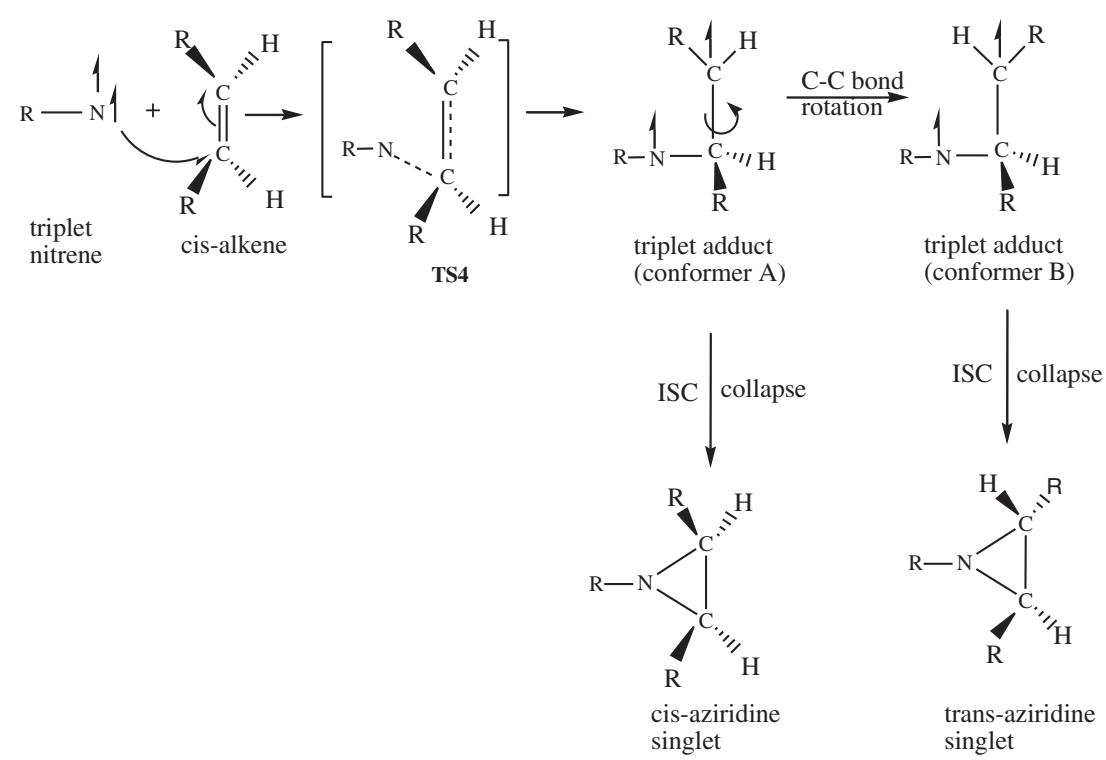

Figure 3. Step-wise mechanism of triplet nitrene addition to alkene to form aziridine. 
the aziridine products. The triplet diradical in conformers $\mathbf{A}$ and $\mathbf{B}$ undergoes ISC and spin coupling to yield the singlet ground state aziridine as two isomers (cis and trans) for both the cis- and trans-alkene substrates.

\subsection{Aims and Objectives}

This computational study has the following aims and objectives:

a. To use DFT and MP2 methods to study the two proposed mechanisms for aziridination of alkenes by singlet and triplet nitrenes derived from azide precursors. The results are to be compared with the scanty experimental and computational data available to gauge whether it is the DFT or the MP2 strategy which is closer to experiment and higher level theory.

b. To note the effects on aziridination by different $\mathbf{R}$ groups in the nitrene, and of methyl substitution in the alkene substrates.

c. To relate transition state geometries to the Hammond postulate. ${ }^{63}$ This states that for one-step reactions with modest activation barriers, exothermic reactions proceed via "early" transition states which resemble the reactants in geometry and energy, and vice versa for endothermic reactions. Geometry parameters discussed include relevant bond lengths and bond angles.

\section{Experimental}

\subsection{Computational Methods}

The B3LYP method ${ }^{64,65}$ with a $6-31 \mathrm{G}(\mathrm{d}, \mathrm{p})$ basis set was used to study the two mechanisms described above, with an unrestricted approach for triplet states. The triplet nitrenes and triplet biradicals studied here gave $<\mathrm{S}^{2}>$ values close to 2 (ranging from 2.0065 to 2.0276) pointing to essentially no spin contamination. For the thermal decomposition reaction of azides, the B3LYP results were compared with B2PLYP results which used B3LYP zero point energy corrections. This reaction was also studied by MP2 theory with aug-cc-pVDZ and aug-cc-pVTZ basis sets to see if the DFT and MP2 approaches yield the same qualitative trends. Other reactions were treated using only the B3LYP method. Transition states were located by a reverse search strategy interpolating between reactants and products to yield a saddle point. Vibrational frequency analyses characterized all species either as energy minima or as transition states. Zero point vibrational energies were corrected by a frequency scaling factor of 0.9806 for the B3LYP results, ${ }^{66}$ and 0.954 for the MP2/aug-cc-pVDZ strategy. ${ }^{67}$

The total energy change or free energy change for any one step is denoted as $\Delta E_{r}$ or $\Delta G_{r}$ respectively, and likewise the activation barrier is denoted as $\Delta E^{f}$ and $\Delta G^{\neq}$(in total energy and free energy terms respectively). Transition state geometry has been described in terms of select internal coordinates. The Gaussian 2009 program suite ${ }^{68}$ was used for all these computations.

\section{Results and Discussion}

\subsection{Thermal Decomposition of Azide}

Table 1 presents the DFT and MP2 values of the decomposition energies $\Delta E_{r}$ and $\Delta G_{r}$ and activation barriers $\Delta E^{\neq}$and $\Delta G^{\neq}$for the decomposition of azide to singlet nitrene along with the singlet-triplet splitting $\Delta E_{S T}$

Table 1. DFT and MP2 values of energy parameters* for thermal decomposition of azide $\mathbf{R}-\mathrm{N}_{3}$ yielding singlet nitrene via TS1 (figure 2a) along with singlet-triplet splitting for the generated nitrene R-N.

\begin{tabular}{lllllll}
\hline $\mathbf{R}$ group & $\Delta E_{r}$ & $\Delta E^{\neq}$ & $\Delta G_{r}$ & $\Delta G^{\neq}$ & $\Delta E_{S T}$ & $\Delta G_{S T}$ \\
\hline DFT results $^{a}$ & & & & & & \\
$\mathrm{H}$ & $29.34(31.32)$ & $52.66(54.37)$ & $20.48(25.23)$ & $50.66(61.30)$ & 13.64 & 14.31 \\
$\mathrm{Me}$ & $14.02(17.25)$ & $39.40(42.23)$ & $4.13(7.22)$ & $38.23(40.32)$ & 11.86 & 12.50 \\
$\mathrm{Et}$ & $13.47(16.11)$ & $41.95(45.11)$ & $3.47(6.99)$ & $40.54(45.11)$ & 9.60 & 10.24 \\
Pr $^{\mathrm{i}}$ & $12.82(14.99)$ & $40.43(43.65)$ & $2.04(4.78)$ & $38.93(45.65)$ & 7.76 & 7.92 \\
$\mathrm{Ac}$ & $16.75(18.51)$ & $28.12(32.43)$ & $6.04(8.98)$ & $26.86(30.76)$ & -5.29 & -6.33 \\
$\mathrm{Ph}$ & $30.85(33.10)$ & $35.31(39.21)$ & $20.18(23.65)$ & $33.91(37.64)$ & 31.24 & 31.46 \\
$\mathrm{MP} 2$ results $^{b}$ & & & & & & \\
$\mathrm{H}$ & $51.45(73.73)$ & $65.55(80.11)$ & $49.44(59.00)$ & $56.74(69.87)$ & 55.51 & 56.16 \\
$\mathrm{Ac}$ & $13.94(40.52)$ & $35.82(45.65)$ & $3.38(17.64)$ & $34.49(47.34)$ & -8.93 & -9.02 \\
$\mathrm{Ph}$ & $36.49(65.73)$ & $42.95(71.35)$ & $25.72(38.56)$ & $41.48(54.34)$ & 25.27 & 25.11 \\
\hline
\end{tabular}

*All energy terms are in $\mathrm{kcal} / \mathrm{mol}$

${ }^{a}$ B $3 L Y P / 6-31 G^{* *}$ values, with B2PLYP/6-31G** values in brackets

${ }^{\mathrm{b}} \mathrm{MP} 2 /$ aug-cc-pVDZ values with MP2/aug-cc-pVTZ values in brackets 
and $\Delta G_{S T}$ for the generated nitrenes. The B3LYP/6$31 \mathrm{G}^{* *}$ values are shown with the B2PLYP/6-31G** values in brackets. The MP2 method was used with the aug-cc-pVDZ and aug-cc-pVTZ basis sets (the latter values in brackets).

The DFT methods treated six cases, having $\mathbf{R}=\mathrm{H}$, $\mathrm{Me}$, Et, isopropyl $\left(\mathrm{Pr}^{i}\right)$ acetyl $(\mathrm{Ac})$ and phenyl $(\mathrm{Ph})$. The MP2 method treated three cases with $\mathbf{R}=\mathrm{H}$, Ac, and $\mathrm{Ph}$. The B2PLYP/6-31G** results are close to the B3LYP results, both yielding the same orders of magnitude for all energy parameters. For the MP2 results, use of the smaller aug-cc-pVDZ (double seta) basis set gives values of the energy parameters lower than those from the aug-cc-pVTZ (triple zeta) basis set. However, use of both basis sets leads to the same orders of magnitude for the various energy parameters. The MP2 results for the $\mathrm{H}, \mathrm{Ac}$ and $\mathrm{Ph}$ cases produce the same order of magnitude $(\mathrm{H}>\mathrm{Ph}>\mathrm{Ac})$ as the DFT methods for all the energy parameters. So the DFT methods give the same qualitative trends as the MP2 methods.

The B3LYP and B2PLYP results (table 1) predict that the concerted thermal decomposition is possible for all the six azides under consideration. However, such a possibility for the three alkyl azides is discounted by the MP2 results, in which singlet alkylnitrene is not a minimum, and TS1 was not located. The MP2 method predicts $\mathbf{R}-\mathrm{N}$ as a minimum only when $\mathbf{R}$ is $\mathrm{H}, \mathrm{Ac}$ and $\mathrm{Ph}$, not for cases having $\mathbf{R}=\mathrm{Me}$, Et and $\mathrm{Pr}^{\mathrm{i}}$, viz., where $\mathbf{R}$ is an alkyl group having an $\alpha$-hydrogen.

Our values of the barrier height for azide decomposition are compared with experimental values and some other computational results (table 2). For $\mathrm{HN}_{3}$, the reported value of $53.6 \mathrm{kcal} / \mathrm{mol}$ actually refers to the net energy requirement ${ }^{30}$ to obtain singlet $\mathrm{NH}$ from $\mathrm{HN}_{3}$ which should be close to the activation energy for such an exothermic reaction. This value compares well with the barrier height of $51.4 \mathrm{kcal} / \mathrm{mol}$ obtained by the CASPT2//CASSCF strategy, and is also close to our B3LYP value of $52.66 \mathrm{kcal} / \mathrm{mol}$, while our MP2/aug-cc-pVDZ value of $65.55 \mathrm{kcal} / \mathrm{mol}$ is appreciably higher (the MP2/aug-cc-pVTZ values being even higher). For the case of $\mathrm{MeN}_{3}$, the experimentally estimated value of $40.5 \mathrm{kcal} / \mathrm{mol}$ for the activation energy is quite close to the various computationally derived values, including our B3LYP/6-31G(d,p) value, where the B3LYP/6-311+G(d,p) value is the one closest to experiment. For the case of $\mathrm{EtN}_{3}$, the various computed values agree fairly well with the experimental value. ${ }^{69}$ It appears from these comparisons that the B3LYP method fares better than the MP2 method or even the rigorous MP4SDQT(Full)/6-311+G**//MP2 (Full)//6-311+G** strategy.

The B3LYP, B2PLYP and MP2 values of $\Delta E_{r}$ and $\Delta G_{r}$ predict azide decomposition to be endothermic for all cases. The endothermicity order given by $\Delta G_{r}$ with respect to $\mathbf{R}$ is $\mathrm{H}>\mathrm{Ph}>\mathrm{Ac}>\mathrm{Me}>\mathrm{Et}>\mathrm{Pr}^{\mathrm{i}}$. For the same cases the endothermicity order predicted by the MP2 method is $\mathrm{H}>\mathrm{Ph}>$ Ac. MP2 values of $\Delta E_{r}$ and $\Delta G_{r}$ for $\mathrm{HN}_{3}$ are larger than the B3LYP values, though for $\mathrm{PhN}_{3}$ and $\mathrm{AcN}_{3}$ both methods are more comparable.

The B3LYP activation barriers range from 28.12 to $52.66 \mathrm{kcal} / \mathrm{mol}$ ( $\Delta E^{\neq}$values) and from 26.86 to

Table 2. Comparison of various estimates of activation energies and barrier heights for the thermal decomposition of alkyl azides (all values in $\mathrm{kcal} / \mathrm{mol}$ ). References in text.

\begin{tabular}{|c|c|c|c|c|c|}
\hline Activation energy (exptl.) & Ref. & Barrier height (theoret.) & Ref. & Method & Values reported here \\
\hline \multicolumn{6}{|l|}{$\mathrm{HN}_{3}$} \\
\hline 53.6 & 30 & 51.4 & 38 & $\begin{array}{l}\text { CASPT2/cc-pVTZ// } \\
\text { CAS/cc-pVDZ }\end{array}$ & $\begin{array}{l}52.66 \text { (B3LYP) } \\
65.55 \text { (MP2) }\end{array}$ \\
\hline \multicolumn{6}{|l|}{$\mathrm{CH}_{3} \mathrm{~N}_{3}$} \\
\hline \multirow[t]{4}{*}{40.5} & 32 & 41.9 & 38 & $\begin{array}{l}\text { CASPT2/cc-pVTZ// } \\
\text { CAS/cc-pVDZ }\end{array}$ & 39.40 (B3LYP) \\
\hline & & 40.8 & 35 & $\begin{array}{l}\text { CAS-MP2/6-31G*// } \\
\text { CASSCF/6-31G* }\end{array}$ & \\
\hline & & 40.68 & 36 & B3LYP/6-311+G(d,p) & \\
\hline & & 43.30 & 36 & $\begin{array}{l}\text { MP4SDQT(Full)/6-311+G**// } \\
\text { MP2(Full)/6-311+G** }\end{array}$ & \\
\hline \multirow{4}{*}{$\begin{array}{l}\mathbf{C}_{\mathbf{2}} \mathbf{H}_{\mathbf{5}} \mathbf{N}_{\mathbf{3}} \\
40.1\end{array}$} & & & & & \\
\hline & 69 & 43.1 & 38 & $\begin{array}{l}\text { CASPT2/cc-pVTZ// } \\
\text { CAS/cc-pVDZ }\end{array}$ & 41.95 (B3LYP) \\
\hline & & 41.9 & 35 & $\begin{array}{l}\text { CAS-MP2/6-31G*// } \\
\text { CAS-MP2/6-31G*// }\end{array}$ & \\
\hline & & 45.78 & 36 & $\begin{array}{l}\text { MP4SDQT(Full)/6-311+G**// } \\
\text { MP2(Full)//6-311+G** }\end{array}$ & \\
\hline
\end{tabular}

*All energy terms are in $\mathrm{kcal} / \mathrm{mol}$ 
$50.66 \mathrm{kcal} / \mathrm{mol}\left(\Delta G^{\neq}\right.$values). The single point B2PLYP values are similar to the B3LYP results. The order of magnitude with respect to the $\mathbf{R}$ group is $\mathrm{H}>(\mathrm{Me}, \mathrm{Et}$, $\left.\operatorname{Pr}^{\mathrm{i}}\right)>\mathrm{Ph}>$ Ac. MP2 values for the three cases studied $(\mathbf{R}=\mathrm{H}, \mathrm{Ac}$ and $\mathrm{Ph})$ give activation barriers falling in the order $\mathrm{H}>\mathrm{Ph}>\mathrm{Ac}$, reproducing the B3LYP and B2PLYP orders for these cases.

The MP2 prediction that the ground state alkyl azide does not decompose concertedly to singlet alkylnitrene is corroborated by many post-HF computational studies, however, the B3LYP method predicts a concerted pathway. CASSCF and CASPT2 studies $^{59}$ do predict the existence of singlet Me-N as an intermediate which rearranges through tunneling.

Studies on methyl azide thermal decomposition ${ }^{31,32}$ did not detect singlet methylnitrene. A CISD study ${ }^{58}$ predicted no barrier for rearrangement of $\mathrm{Me}-\mathrm{N}$ to $\mathrm{CH}_{2}=\mathrm{NH}$ on the lowest lying singlet surface, suggesting $\mathrm{MeN}$ is not a minimum. QCISD(T)//UMP2/6$31 \mathrm{G}(\mathrm{d}, \mathrm{p})$ studies did not predict singlet $\mathrm{MeN}$ as a minimum. ${ }^{34}$ The CAS/MP2 approach (with CAS calculations using the MP2 function as the zeroth order function ${ }^{35}$ ) gave no concerted route for thermal decomposition of methyl azide via extrusion of $\mathrm{N}_{2}$. A stepwise route giving triplet Me-N and $\mathrm{N}_{2}$ was located, where spin-allowed and spin-forbidden routes both gave barriers around $41 \mathrm{kcal} / \mathrm{mol}$. An activation energy of $40.5 \mathrm{kcal} / \mathrm{mol}$ was assigned to this reaction ${ }^{32}$ by referring to the crossing point $40.7 \mathrm{kcal} / \mathrm{mol}$ above the ground state reactant located by the CAS/MP2 method. ${ }^{35}$ The values of these energy terms are close to our DFT values for $\Delta E^{\neq}$and $\Delta G^{\neq}$(38.23 to 40.32 $\mathrm{kcal} / \mathrm{mol}$ ). Similar behavior was predicted for $\mathrm{HN}_{3}$, $\mathrm{MeN}_{3}$ and $\mathrm{EtN}_{3}$ by a CASPT2//CASSCF study, ${ }^{38}$ with intersection of singlet and triplet surfaces. Our B3LYP values of barriers $\Delta E^{\neq}$and $\Delta G^{\neq}$for decomposition of $\mathrm{EtN}_{3}$ and $\mathrm{Pr}^{\mathrm{i}} \mathrm{N}_{3}$ range from 38.93 to $41.95 \mathrm{kcal} / \mathrm{mol}$ (close to our values for $\mathrm{MeN}_{3}$ decomposition).

Our DFT and MP2 results both predict that singlet acetyl azide can yield singlet Ac-N in concerted fashion via transition state TS2. Decomposition of acetyl and benzoyl azides to the isocyanate and $\mathrm{N}_{2}$ has been studied earlier at the (MP2)(full)/6-31G* level, ${ }^{39}$ identifying a dissociation path involving singlet acylnitrene. However, CCSD(T) and CBS-QB3 studies $^{62}$ predicted acetyl azide decomposes by methyl group migration to give methyl isocyanate and $\mathrm{N}_{2}$ with a barrier of $27 \mathrm{kcal} / \mathrm{mol}$. Experimentally, photolysis of pivaloyl azide gives singlet pivaloyl nitrene, ${ }^{45}$ which adds to $\mathrm{C}=\mathrm{C}$ double bonds and inserts into $\mathrm{C}-\mathrm{H}$ bonds.

Methyl 1,2 shift in $\mathrm{AcN}_{3}$ gives methyl isocyanate, where our B3LYP values of $\Delta E_{r}$ and $\Delta G_{r}(-55.95$ and $-67.03 \mathrm{kcal} / \mathrm{mol}$ ) indicate high exothermicity. The B3LYP barriers $\Delta E^{\neq}$and $\Delta G^{\neq}$for this reaction (28.38 and $27.22 \mathrm{kcal} / \mathrm{mol}$ respectively) approach the $\operatorname{CCSD}(\mathrm{T})$ value of $27 \mathrm{kcal} / \mathrm{mol},{ }^{62}$ but are also close to our $\Delta E^{\neq}$and $\Delta G^{\neq}$values for acetylnitrene generation (28.12 and $26.86 \mathrm{kcal} / \mathrm{mol}$ in table 1). These B3LYP results thus predict similar likelihoods for nitrene generation and rearrangement to isocyanate.

Phenyl azide decomposition to phenylnitrene has not been studied before, but reactions like ring expansion of phenylnitrene have been studied. ${ }^{70-72}$ Generation of singlet phenylnitrene from singlet phenyl azide is endothermic (B3LYP and MP2 values of $\Delta E_{r}$ and $\Delta G_{r}$ ranging from 20.18 to $36.49 \mathrm{kcal} / \mathrm{mol}$ ). The barriers to nitrene generation from $\mathrm{PhN}_{3}$ are fairly large, lower than those for the $\mathrm{HN}_{3}$ and alkyl azide cases, but higher than for the $\mathrm{AcN}_{3}$ case.

1,2-hydride shift is an alternative to dissociative nitrene generation in alkyl azides $\mathbf{R}-\mathrm{N}_{3}(\mathbf{R}=\mathrm{Me}, \mathrm{Et}$ and $\mathrm{Pr}^{\mathrm{i}}$ ). Table 3 gives B3LYP/6-31G(d,p) and MP2/augcc-pVDZ values of energy parameters for this process yielding alkanimines from methyl, ethyl and isopropyl azides. Our MP2 results predict alkyl azides decompose via 1,2-hydride shift to yield alkanimines instead of dissociating to singlet alkylnitrene and $\mathrm{N}_{2}$. The B3LYP results allow for both possibilities. B3LYP and MP2 values of $\Delta E_{r}$, and $\Delta G_{r}$ for 1,2-hydride shift in the three alkyl azides predict the reaction as very exother$\operatorname{mic}\left(\Delta G_{r}=-50.87\right.$ to $\left.-54.11 \mathrm{kcal} / \mathrm{mol}\right)$. The B3LYP results predict that the 1,2 hydride shift is thermodynamically more favorable than decomposition to singlet alkylnitrene and $\mathrm{N}_{2}$.

MP2 and B3LYP values of barriers $\Delta E^{\neq}$and $\Delta G^{\neq}$ for the 1,2-hydride shift range from 34.86 to 43.82

Table 3. MP2/aug-cc-pVDZ and B3LYP/6-31G** values of energy parameters* for alkyl azide decomposition through 1,2 hydride shift forming imine and $\mathrm{N}_{2}$ via TS2 (figure $2 \mathrm{~b}$ ) with B3LYP values in brackets.

\begin{tabular}{lcccc}
\hline R group & $\Delta E_{r}$ & $\Delta E^{\neq}$ & $\Delta G_{r}$ & $\Delta G^{\neq}$ \\
\hline $\mathrm{Me}$ & $-50.87(-42.88)$ & $43.82(40.13)$ & $-60.73(-52.58)$ & $42.76(39.20)$ \\
$\mathrm{Et}$ & $-54.11(-48.02)$ & $42.54(37.32)$ & $-64.32(-58.05)$ & $41.43(36.24)$ \\
$\operatorname{Pr}^{\mathrm{i}}$ & $-54.41(-51.20)$ & $42.26(36.20)$ & $-65.10(-61.89)$ & $41.03(34.86)$
\end{tabular}

*All energy terms are in $\mathrm{kcal} / \mathrm{mol}$ 
$\mathrm{kcal} / \mathrm{mol}$, yielding the order $\mathrm{Me}>\mathrm{Et}>\operatorname{Pr}^{\mathrm{i}}$ for barrier magnitude, where alkyl group branching promotes reaction feasibility. QCISD(T)//MP2/6-31G(d,p) results $^{34}$ gave barrier heights of 41.2 and $37.7 \mathrm{kcal} / \mathrm{mol}$ [with the 6-311++G(d,p) and 6-311++G(3df, 2p) basis sets respectively] for 1,2-hydride shift in methyl azide yielding methanimine and $\mathrm{N}_{2}$, fairly comparable to our MP2 and B3LYP values. However, B3LYP values of the 1,2-hydride shift barriers also fall within the same range as the values for alkylnitrene generation (table 2). Thus, the B3LYP results does not differentiate well between the two outcomes.

\subsection{Transition States for Azide Decomposition}

Transition states TS1 and TS2 for (a) thermal decomposition of azide to singlet nitrene, and for $(b)$ rearrangement of the azide precursor to imine by 1,2 $\mathrm{H}$-shift, are discussed in relation to the Hammond postulate correlating geometry to the energetics of the two reactions.

3.2a Transition state: TS1: figure 4a describes the geometry of TS1 for azide decomposition to singlet nitrene, where the atom $\mathrm{C}_{\mathrm{r}}$ is the $\mathrm{H}$ atom for $\mathrm{H}-\mathrm{N}_{3}$, the $\alpha$-carbon for alkyl azides, and the carbonyl $\mathrm{C}$ atom for acetyl azide. Table 4 presents B3LYP/6-31G** and MP2/aug-cc-pVDZ data for TS1 geometry with Wiberg bond indices $W_{12}$ and $W_{23}$ for the N1-N2 and N2-N3 bonds. The geometry of TS1 is compared with that of the ground state singlet azide.

Due to appreciable endothermicity of azide decomposition, TS1 would be on the 'late' side, resembling the products more than the azide reactant. Late character of TS1 is seen in the large DFT and MP2 values of $R_{1}$, the breaking N1-N2 bond length (1.851 to 2.047 $\AA$ ), the small bond orders $W_{12}(0.277$ to 0.500$)$ and the short N2-N3 bond lengths (close to the MP2 value of $1.130 \AA$ in free $\mathrm{N}_{2}$ ). In the azide, the N1-N2 bond lengths (1.235 to $1.244 \AA$ ) and N1-N2 bond orders (1.426 to 1.524 ) show that TS1 does not resemble the azide reactant. The N2-N3 bond length $R_{2}$ is short in TS1 (about $1.1 \AA$ ), shorter than in the azide reactant. The MP2 and B3LYP bond orders $W_{23}$ for the N2-N3 bond in TS1 (2.846 to 2.992) approach a triple bond situation, unlike in the azide (with smaller $W_{23}$ values). Values of the bond angle $\theta_{1}\left(108.7\right.$ to $\left.110.4^{0}\right)$ suggest $s p^{3}$ character for the $\mathrm{N} 1$ atom in TS1 (as opposed to $s p^{2}$ character in the azide precursor). The angle $\theta_{2}\left(144.5\right.$ to $\left.159.6^{\circ}\right)$ diverges much from the near $180^{\circ}$ values in the azide precursor, pointing to departure from $s p$ hybridization for the $\mathrm{N} 2$ atom. These results thus indicate that the 'late' character in transition state TS1 for this endothermic step, is in good accord with the Hammond postulate.

3.2b Transition state: TS2: Table 5 gives MP2 and B3LYP values of geometry parameters for transition state TS2 for 1,2 hydride shift in the alkyl azide (figure $4 \mathrm{~b}$ ). The appreciable exothermicity of this reaction suggests 'early' transition states. The lengths $R_{c h}$ of the breaking C-H bond in TS2 (1.127 to $1.148 \AA$ ) are shorter than the lengths $R_{n h}$ of the forming N-H bond (1.654 to $1.754 \AA$ ). Values of the dihedral $\varphi\left[\mathrm{C}_{\mathrm{r}}-\mathrm{N} 1-\mathrm{N} 2-\right.$ N3] are close to $180^{\circ}$, indicating planarity of transition state TS2 in a fashion similar to the reactant azide. All these points related to TS2 as an 'early' transition state in good accordance with Hammond's postulate.

\subsection{Nitrene Singlet-Triplet Gaps}

B3LYP values of singlet-triplet energy gaps $\Delta E_{S T}$ and $\Delta G_{S T}$ (table 1) indicate triplet ground states for $\mathrm{HN}$

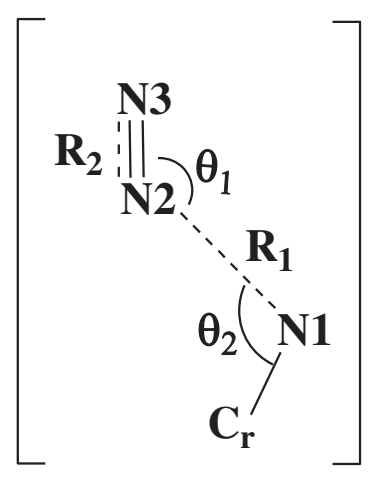

TS 1

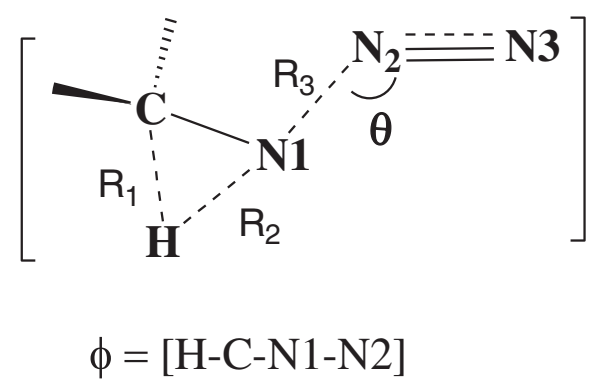

TS 2

(a)

(b)

Figure 4. Geometry descriptors of transition states: (a) TS1 for azide decomposition to singlet nitrene, and (b) TS2 for azide rearrangement to imine by 1,2 H-shift. 
Table 4. B3LYP/6-31G** and MP2/aug-cc-pVDZ values of geometry parameters* for transition state TS1 (figure 4a) for thermal decomposition of azides $\mathbf{R}-\mathrm{N}_{3}$ to singlet nitrene and $\mathrm{N}_{2}$ (figure 2a) and compared with azide reactant geometry (in brackets).

\begin{tabular}{llllllll}
\hline R group & $R 1$ & $R 2$ & $\theta 1$ & $\theta 2$ & $\varphi$ & $W 12$ & $W 23$ \\
\hline B3LYP values & & & & & & & \\
$\mathrm{H}$ & 1.963 & 1.108 & 166.0 & 89.2 & 179.9 & 0.492 & 2.916 \\
& $(1.242)$ & $(1.140)$ & $(171.6)$ & $(109.9)$ & $(180.0)$ & $(1.481)$ & $(2.436)$ \\
$\mathrm{Me}$ & 2.047 & 1.108 & 145.5 & 109.9 & -179.0 & 0.277 & 2.945 \\
& $(1.235)$ & $(1.143)$ & $(172.9)$ & $(115.7)$ & $(-178.8)$ & $(1.524)$ & $(2.239)$ \\
$\mathrm{Et}$ & 1.961 & 1.109 & 146.5 & 110.1 & -178.3 & 0.362 & 2.918 \\
& $(1.234)$ & $(1.143)$ & $(173.3)$ & $(115.7)$ & $(-179.9)$ & $(1.529)$ & $(2.328)$ \\
$\operatorname{Pr}^{\mathrm{i}}$ & 1.948 & 1.110 & 145.9 & 109.7 & -179.8 & 0.374 & 2.908 \\
& $(1.234)$ & $(1.143)$ & $(173.6)$ & $(115.7)$ & $(-177.6)$ & $(1.532)$ & $(2.322)$ \\
$\mathrm{Ac}$ & 1.894 & 1.111 & 144.5 & 110.4 & -179.4 & 0.500 & 2.867 \\
& $(1.244)$ & $(1.138)$ & $(172.8)$ & $(118.0)$ & $(-179.9)$ & $(1.466)$ & $(2.372)$ \\
$\mathrm{Ph}$ & 1.870 & 1.114 & 140.1 & 111.3 & -156.3 & 0.450 & 2.846 \\
& $(1.237)$ & $(1.142)$ & $(172.8)$ & $(118.0)$ & $(-180.0)$ & $(1.488)$ & $(2.343)$ \\
$\mathrm{MP} 2$ values & & & & & & & \\
$\mathrm{H}$ & 1.970 & 1.132 & 168.0 & 88.7 & -179.7 & 0.295 & 2.992 \\
& $(1.259)$ & $(1.161)$ & $(170.8)$ & $(109.2)$ & $(179.8)$ & $(1.481)$ & $(2.436)$ \\
$\mathrm{Ac}$ & 1.804 & 1.134 & 150.6 & 108.7 & 179.9 & 0.425 & 2945 \\
& $(1.238)$ & $(1.150)$ & $(172.8)$ & $(117.4)$ & $(179.9)$ & $(1.426)$ & $(2.454)$ \\
$\mathrm{Ph}$ & 1.851 & 1.140 & 143.3 & 108.8 & -158.0 & 0.342 & 2.942 \\
& $(1.251)$ & $(1.165)$ & $(172.7)$ & $(116.0)$ & $(179.9)$ & $(1.451)$ & $(2.420)$ \\
\hline
\end{tabular}

*Distances in angstrom; angles in degrees

Table 5. MP2/aug-cc-pVDZ and B3LYP/6-31G** values of geometry parameters* of TS2 (figure 4b) for decomposition via 1,2 hydride shift of alkyl azides (B3LYP values given in brackets).

\begin{tabular}{llllll}
\hline Alkene & $R_{1}$ & $R_{2}$ & $R_{3}$ & $\theta$ & $\varphi$ \\
\hline $\mathrm{Me}$ & 1.133 & 1.754 & 1.924 & 107.5 & 179.9 \\
$\mathrm{Et}$ & $(1.127)$ & $(1.754)$ & $(2.051)$ & $(104.4)$ & $(179.9)$ \\
& 1.141 & 1.712 & 1.888 & 107.0 & 177.0 \\
$\operatorname{Pr}^{\mathrm{i}}$ & $(1.138)$ & $(1.683)$ & $(1.978)$ & $(109.4)$ & $(178.7)$ \\
& 1.148 & 1.682 & 1.869 & 106.1 & 180.0 \\
& $(1.145)$ & $(1.654)$ & $(1.941)$ & $(109.4)$ & $(180.0)$ \\
\hline
\end{tabular}

*Bond distances in Angstrom; angles in degrees

and the alkylnitrenes MeN, EtN and $\operatorname{Pr}^{\mathrm{i}} \mathrm{N}$. Magnitude of the splittings follow the order $\mathrm{HN}>\mathrm{MeN}>\mathrm{EtN}>$ $\operatorname{Pr}^{\mathrm{i}} \mathrm{N}$. The B3LYP singlet-triplet splitting is somewhat larger for $\mathrm{HN}$ than for $\mathrm{MeN}$. For $\mathrm{NH}$, our MP2 value of $\Delta E_{S T}(52.80 \mathrm{kcal} / \mathrm{mol})$ may be compared with the CASSCF value of $45.5 \mathrm{kcal} / \mathrm{mol},{ }^{35}$ both values noticeably larger than our B3LYP value of $13.64 \mathrm{kcal} / \mathrm{mol}$. For MeN, our B3LYP value of $\Delta E_{S T}(11.86 \mathrm{kcal} / \mathrm{mol})$ is much lower than CASPT2 value of $38.1 \mathrm{kcal} / \mathrm{mol}^{38}$ and an experimental estimate of $31.2 \pm 2 \mathrm{kcal} / \mathrm{mol} .{ }^{73}$

Acetylnitrene is predicted by our B3LYP and MP2 results to have a singlet ground state, with B3LYP and MP2 values for $\Delta E_{S T}$ (table 1) as -5.29 and $-10.03 \mathrm{kcal} / \mathrm{mol}$. Earlier studies on acylnitrenes ${ }^{53}$ gave conflicting results, but the more accurate studies predict singlet ground states for such species. Interaction between the oxygen and the nitrogen atoms stabilizes the singlet state for acylnitrenes. Our B3LYP and MP2 results assign a triplet ground state for phenylnitrene in accordance with earlier results reviewed. ${ }^{53}$ The B3LYP singlet-triplet gap is larger than for other nitrenes in this series, though the MP2 value is lower than that for HN.

\subsection{Concerted Insertion of Free Singlet Nitrene}

This reaction is studied using the B3LYP method for singlet $\mathrm{HN}, \mathrm{MeN}$ and $\mathrm{AcN}$. We assume the nitrene, immediately upon generation as a singlet from the azide, finds time to insert into the alkene $\mathrm{C}=\mathrm{C}$ bond before decay to the triplet ground state. The singlet nitrene may also arise from ISC of triplet nitrene, or from photochemical pathways (not studied here). 
Pentafluorophenylnitrene and sulfonyl nitrene are also known to insert into alkenes. ${ }^{42,43}$

This concerted reaction via transition state TS3 (figure 2c) is stereospecific in contrast to insertion reaction by triplet nitrene. For the asymmetrical propene case, the nitrene substituent $\mathbf{R}$ may point away from or towards the propene methyl group (orientations $\mathrm{A}$ and $\mathrm{B}$ respectively). TS3 was detected for the insertion reaction of $\mathrm{MeN}$ and $\mathrm{AcN}$ into ethene but not for insertion of $\mathrm{HN}$ into ethene. MRD CI results ${ }^{54}$ also predicted that insertion of singlet $\left({ }^{1} \Delta\right) \mathrm{HN}$ into ethene occurs virtually without a barrier to form singlet ground state aziridine.

Table 6 gives B3LYP values of $\Delta E_{r}$ and $\Delta G_{r}$ (energy changes for insertion), all large and negative ( $\Delta E_{r}$ ranging from -58.33 to $-72.80 \mathrm{kcal} / \mathrm{mol}$ ). The high exothermicity of the insertion reaction is in line with formation of two new N-C singlet bonds. The facility order $\mathrm{H}>\mathrm{Ac}>\mathrm{Me}$ with respect to nitrene substituent holds for all alkene substrates. Our B3LYP $\Delta E_{r}$ value of $-71.32 \mathrm{kcal} / \mathrm{mol}$ for singlet $\mathrm{NH}$ insertion into ethene approaches the MRD CI value of -77.3 $\mathrm{kcal} / \mathrm{mol}$ but falls short of the "full" CI value of -82.9 $\mathrm{kcal} / \mathrm{mol}$ or the value of $-103.2 \mathrm{kcal} / \mathrm{mol}$ deduced from thermochemical data. ${ }^{54}$

Nitrene insertion reaction is interpreted here as electrophilic addition of electron-deficient nitrene to the electron-rich $\mathrm{C}=\mathrm{C}$ bond of the alkene. Thus, MeN insertion is thermodynamically less facile than $\mathrm{NH}$ insertion (or addition) due to the electron-donating $\mathrm{Me}$ substituent. For the propene case, orientation A is thermodynamically favored over orientation $\mathrm{B}$, attributable to steric factors. Successive methyl substitution on the alkene substrate does not affect much the values of $\Delta E_{r}$ and $\Delta G_{r}$, while effects of the substituent $\mathbf{R}$ in the nitrene are more pronounced.

Values of the nitrene addition barriers $\Delta E^{\neq}$and $\Delta G^{\neq}$are give in table 6 for the $\mathrm{MeN}$ and $\mathrm{AcN}$ cases (not the $\mathrm{HN}$ case). The $\Delta E^{\neq}$values (5.67 to $25.16 \mathrm{kcal} / \mathrm{mol}$ ) are lower than $\Delta G^{\neq}$values (14.49 to $33.90 \mathrm{kcal} / \mathrm{mol}$ ) by $8-10 \mathrm{kcal} / \mathrm{mol}$, pointing to marked entropy effects. Barriers are appreciable for methylnitrene insertion ( $\Delta G^{\neq}$from 25.46 to $33.90 \mathrm{kcal} / \mathrm{mol}$ ), but lower for acetylnitrene insertion $\left(\Delta G^{\neq}\right.$from 14.49 to $17.46 \mathrm{kcal} / \mathrm{mol}$ ). Successive methyl substitution on the alkene augments kinetic facility of the reaction since nucleophilicity of the $\mathrm{C}=\mathrm{C}$ bond is enhanced through methyl substitution. cis-2-Butene is a more favorable substrate than trans-2-butene due to steric factors. The low barriers for the acetylnitrene case $\left(\Delta E^{\neq}\right.$from 5.67 to $8.71 \mathrm{kcal} / \mathrm{mol}$ ) reflect the low barrier of 6.7 $\mathrm{kcal} / \mathrm{mol}$ obtained earlier by B3LYP/6-31G(d,p) studies on formylnitrene insertion into ethene. ${ }^{61}$ Electronwithdrawing acyl groups enhance nitrene electrophilicity in this electrophilic addition reaction. In fact, acetylnitrene insertion into ethene was predicted by high level theory $^{62}$ to proceed with a near zero enthalpic barrier or with small free energy barriers controlled by entropy.

Table 6 presents values of geometry descriptors for transition state TS3 (figure 5a). Due to the high exothermicity of insertion, TS3 is expected to be 'early'. The forming N-C1 and N-C2 bonds are long (2.749 to 2.924 A) with small values of the bond indices ( 0.102 to 0.102 a.u.). The apical $\mathrm{C} 1-\mathrm{N}-\mathrm{C} 2$ angle $\theta$ is quite acute (27.4 to $28.6^{\circ}$ ). The dihedral $\phi$ spanning the $\mathrm{C}-\mathrm{N}-\mathrm{C} 1-\mathrm{C} 2$ atoms

Table 6. B3LYP/6-31G** values* of energy terms associated with direct insertion of singlet nitrene R-N into alkenes via transition state TS3 (figure 3) along with geometry parameters associated with transition state TS3 (figure 5a).

\begin{tabular}{|c|c|c|c|c|c|c|c|c|}
\hline Alkene & $\Delta E_{r}$ & $\Delta E^{\neq}$ & $\Delta G_{r}$ & $\Delta G^{\neq}$ & $R_{1}$ & $R_{2}$ & $\theta$ & $\varphi$ \\
\hline \multicolumn{9}{|l|}{$\mathbf{R}=\mathbf{H}$} \\
\hline Ethene & -71.32 & - & -61.26 & - & - & - & - & - \\
\hline Propene & -71.88 & - & -60.78 & - & - & - & - & - \\
\hline cis-2-Butene & -72.80 & - & -61.74 & - & - & - & - & - \\
\hline trans-2-Butene & -72.37 & - & -61.11 & - & - & - & - & - \\
\hline \multicolumn{9}{|l|}{$\mathbf{R}=\mathbf{M e}$} \\
\hline Ethene & -58.33 & 25.16 & -46.23 & 33.90 & 2.747 & 2.746 & 28.2 & 96.6 \\
\hline Propene A & -58.91 & 24.20 & -45.86 & 33.56 & 2.803 & 2.772 & 27.8 & 101.6 \\
\hline Propene B & -55.92 & 16.87 & -42.89 & 26.02 & 2.727 & 2.709 & 28.5 & 106.0 \\
\hline cis-2-Butene & -59.99 & 23.46 & -46.95 & 32.43 & 2.806 & 2.805 & 27.7 & 97.0 \\
\hline trans-2-Butene & -56.67 & 17.20 & -43.53 & 25.46 & 2.933 & 2.931 & 26.5 & 83.3 \\
\hline \multicolumn{9}{|l|}{$\mathbf{R}=\mathbf{A c}$} \\
\hline Ethene & -63.94 & 8.71 & -52.26 & 17.46 & 2.756 & 2.756 & 28.2 & 96.0 \\
\hline Propene A & -64.91 & 6.83 & -52.03 & 16.72 & 2.834 & 2.712 & 27.9 & 100.9 \\
\hline Propene B & -63.45 & 7.30 & -50.28 & 16.95 & 2.726 & 2.620 & 26.3 & 100.6 \\
\hline cis-2-Butene & -66.25 & 5.67 & -53.39 & 14.49 & 2.817 & 2.817 & 27.7 & 97.5 \\
\hline trans-2-Butene & -64.59 & 5.68 & -51.53 & 15.35 & 2.944 & 2.950 & 27.4 & 112.4 \\
\hline
\end{tabular}

*Energy terms in $\mathrm{kcal} / \mathrm{mol}$; distances in angstrom; angles in degrees 


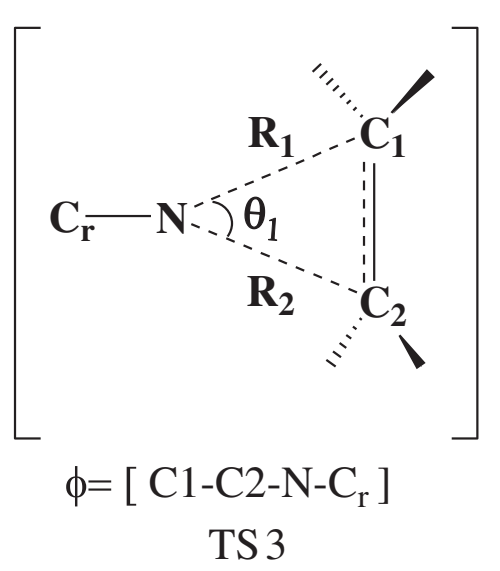

(a)

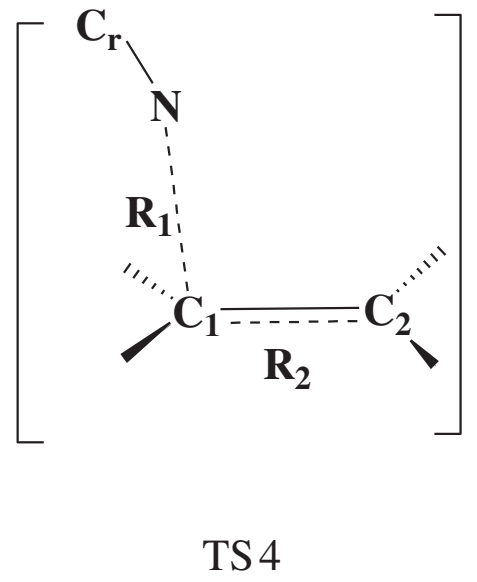

(b)

Figure 5. Select geometry descriptors for transition states: (a) TS3 for the concerted insertion of singlet nitrene into alkenes, and (b) TS4 for addition of triplet nitrene to alkenes (initial step forming diradical).

ranges from 96.0 to $117.5^{\circ}$, so the $\mathbf{R}$ group in $\mathbf{T S 3}$ is roughly perpendicular to the $\mathrm{N}-\mathrm{C} 1-\mathrm{C} 2$ moiety. These features appear in B3LYP and QBS/6-31G(d) studies on acetylnitrene addition to ethene, ${ }^{62}$ with 'early' transition states having long forming $\mathrm{C}-\mathrm{N}$ bonds and small barriers.

\subsection{Stepwise Addition of Triplet Nitrene}

Addition of triplet nitrene to an alkene $\mathrm{C}=\mathrm{C}$ bond results in aziridine formation as shown in figure 3 with a cis alkene substrate. Table 7 presents B3LYP/6-31G** values of energy terms for addition of triplet nitrene $\mathbf{R}$ $\mathrm{N}$ to alkene $\mathrm{C}=\mathrm{C}$ bonds via transition state TS4. The initial step of addition of triplet nitrene is described by the energy changes $\Delta E_{r}(1)$ and $\Delta G_{r}(1)$ and the barriers $\Delta E^{\neq}$and $\Delta G^{\neq}$. Table 7 also presents the energy changes $\Delta E_{r}(2)$ and $\Delta G_{r}(2)$ for cyclization of the triplet diradical (via ISC) to form the singlet aziridine.

Triplet NH adds to alkenes via formation of the intermediate triplet diradical. ${ }^{51,54}$ This non-stereospecific addition requires that the rate of $\mathrm{C}-\mathrm{C}$ bond rotation in the triplet diradical be of comparable magnitude to the rate of spin inversion. The triplet nitrene may be generated from the singlet ground state azide via the ISC intersection point described in earlier work ${ }^{36-38}$ or else by ISC of the singlet nitrene initially generated from the azide (e.g., by photolysis).

The negative values of $\Delta E_{r}(1)$ predict exothermicity for triplet nitrene addition to alkene, more for the $\mathrm{HN}$ and $\mathrm{AcN}$ cases $\left[\Delta E_{r}(1)=-9.90\right.$ to -13.78 $\mathrm{kcal} / \mathrm{mol}$ ] than for the MeN case $\left[\Delta E_{r}(1)=-0.34\right.$ to $-5.26 \mathrm{kcal} / \mathrm{mol}]$. For triplet $\mathrm{NH}$ addition to ethene, our negative B3LYP value of $-13.47 \mathrm{kcal} / \mathrm{mol}$ for $\Delta E_{r}(1)$ contrasts with the positive values of $3.6 \mathrm{kcal} / \mathrm{mol}(\mathrm{CI}$, $\mathrm{T} \rightarrow 0$ method) and $2.8 \mathrm{kcal} / \mathrm{mol}$ ("full" CI method) obtained earlier. ${ }^{54}$ Methyl substitution in the alkene reduces thermodynamic facility of addition. The propene $\mathbf{A}$ option is more facile than the propene $\mathbf{B}$ option due to steric effects of the methyl group. Values of the free energy change $\Delta G_{r}(1)$ are much less negative than the $\Delta E_{r}(1)$ values, indicating entropy effects.

The barriers $\Delta E^{\neq}$and $\Delta G^{\neq}$values predict kinetic facility in the order $\mathrm{Me}<\mathrm{H}<$ Ac with respect to the nitrene $\mathbf{R}$ group, the same as that for thermodynamic facility. Our B3LYP value of $7.59 \mathrm{kcal} / \mathrm{mol}$ for the barrier height of triplet $\mathrm{NH}$ addition to ethene may be compared with the larger values of $29.3 \mathrm{kcal} / \mathrm{mol}$ (CI, T $\rightarrow 0$ ) and $26.9 \mathrm{kcal} / \mathrm{mol}$ ("full" $\mathrm{CI}$ ) obtained using a $4-31 \mathrm{G}^{* *}$ basis set. $^{54}$

Scope for rotation of the triplet diradical adduct around the C-C single bond leads to loss of stereochemical integrity for formation of aziridine from triplet nitrene and alkene. This can occur for cis- 2-butene and trans 2-butene through conformers $\mathbf{A}$ and $\mathbf{B}$ of the triplet diradical adduct. They differ in energy only to a small extent. For cis- and trans 2-butene, a mixture of cis- and trans 2,3-dimethylaziridines would result from both these alkenes.

The net energy changes accompanying triplet diradical ISC and cyclization, given as $\Delta E_{r}(2)$ and $\Delta G_{r}(2)$, have large negative values $(-40.29$ to $-49.71 \mathrm{kcal} / \mathrm{mol})$ indicating the exothermicity of this process, strain in the cyclic product notwithstanding. The two values given for $\Delta E_{r}(2)$ and $\Delta G_{r}(2)$ in the cases of cis and trans 2-butene correspond to the isomeric products (cisand trans-aziridines) obtained from both, where transaziridine is the more stable isomer. 
Table 7. B3LYP/6-31G** values of energy parameters* for triplet nitrene addition to alkene via TS4 and collapse to aziridine as shown in figure 3 .

\begin{tabular}{|c|c|c|c|c|c|c|c|c|}
\hline Alkene & $\Delta E_{r}(1)$ & $\Delta E^{\neq}$ & $\Delta G_{r}(1)$ & $\Delta G^{\neq}$ & $\Delta E_{r}(2)$ & $\Delta G_{r}(2)$ & $R_{1}$ & $R_{2}$ \\
\hline \multicolumn{9}{|l|}{$\mathbf{R}=\mathbf{H}$} \\
\hline Ethene & -13.47 & 7.59 & -5.78 & 15.47 & -44.19 & -41.18 & 2.100 & 1.367 \\
\hline Propene A & -12.92 & 4.26 & -4.90 & 13.12 & -45.29 & -41.57 & 2.111 & 1.367 \\
\hline Propene B & -11.41 & 5.64 & -1.90 & 14.96 & -46.81 & -44.57 & 2.094 & 1.371 \\
\hline cis-2-Butene & -12.04 & 5.26 & -3.06 & 14.04 & -47.11 & $\begin{array}{l}-44.36 \\
(-47.92)\end{array}$ & $\begin{array}{l}2.103 \\
(-44.98)\end{array}$ & 1.376 \\
\hline trans-2-Butene & -10.80 & 5.38 & -1.82 & 14.48 & -47.92 & $\begin{array}{l}-44.98 \\
(-47.11)\end{array}$ & $\begin{array}{l}2.097 \\
(-44.36)\end{array}$ & 1.373 \\
\hline \multicolumn{9}{|l|}{$\mathbf{R}=\mathbf{M e}$} \\
\hline Ethene & -5.26 & 10.67 & 5.78 & 20.11 & -43.35 & -40.29 & 2.004 & 1.376 \\
\hline Propene A & -4.00 & 10.55 & 5.93 & 21.06 & -43.06 & -39.27 & 2.009 & 1.378 \\
\hline Propene B & -1.93 & 11.80 & 9.14 & 22.72 & -45.12 & -42.49 & 2.002 & 1.381 \\
\hline cis-2-Butene & -3.21 & 11.27 & 6.92 & 21.23 & -44.92 & $\begin{array}{l}-41.37 \\
(-44.48)\end{array}$ & $\begin{array}{l}2.015 \\
(-41.01)\end{array}$ & 1.386 \\
\hline trans-2-Butene & -0.34 & 11.62 & 9.99 & 22.43 & -44.48 & $\begin{array}{l}-41.01 \\
(-44.92)\end{array}$ & $\begin{array}{l}2.009 \\
(-41.37)\end{array}$ & 1.384 \\
\hline \multicolumn{9}{|l|}{$\mathbf{R}=\mathbf{A c}$} \\
\hline Ethene & -13.78 & 4.11 & -3.58 & 13.98 & -44.86 & -42.38 & 2.092 & 1.370 \\
\hline Propene A & -13.34 & 2.84 & -3.15 & 13.05 & -46.27 & -42.55 & 2.106 & 1.371 \\
\hline Propene B & -9.90 & 4.52 & 1.63 & 15.73 & -49.71 & -47.33 & 2.068 & 1.380 \\
\hline cis-2-Butene & -11.98 & 5.43 & -0.80 & 15.53 & -48.97 & $\begin{array}{l}-46.27 \\
(-48.08)\end{array}$ & $\begin{array}{l}2.113 \\
(-44.61)\end{array}$ & 1.384 \\
\hline trans-2-Butene & -11.21 & 2.65 & -0.59 & 13.89 & -48.08 & $\begin{array}{l}-44.61 \\
(-48.97)\end{array}$ & $\begin{array}{l}2.092 \\
(-46.27)\end{array}$ & 1.380 \\
\hline
\end{tabular}

*Energy terms in $\mathrm{kcal} / \mathrm{mol}$; distances in angstrom

B3LYP/6-31G** values of geometry parameters for transition state TS4 for addition of triplet nitrene R-N into alkenes, defined in figure $5 \mathrm{~b}$, are given in Table 7 , which gives the bond length $R_{1}$ for the forming N-C bond in TS4, and bond length $R_{2}$ for the C-C bond in TS4. For any given alkene case, the forming $\mathrm{N}-\mathrm{C}$ bond length $R_{1}$ has longer values for cases where $\mathbf{R}=\mathrm{H}$ and $\mathbf{R}=$ Ac (more appreciably exothermic) than for cases where $\mathrm{R}=\mathrm{Me}$ (less exothermic), pointing to earlier transition states for $\mathbf{R}=\mathrm{H}$ or Ac. This is also seen in the $\mathrm{C}-\mathrm{C}$ bond lengths $R_{2}$ (shorter for cases when $\mathbf{R}=$ $\mathrm{H}$ or Ac than for cases where $\mathbf{R}=\mathrm{Me}$ ). These observations regarding relative "earliness" of TS4 is in accord well with the Hammond postulate.

\section{Conclusions}

This computational study of the putative role of discrete nitrene species for aziridination of alkenes by azides leads to the following conclusions:

a. B3LYP and MP2 results both predict that thermal decomposition of $\mathrm{HN}_{3}, \mathrm{PhN}_{3}$ and $\mathrm{AcN}_{3}$ to their respective singlet nitrenes can occur in a concerted manner with large activation barriers which fall in the order $\mathrm{HN}_{3}>\mathrm{PhN}_{3}>\mathrm{AcN}_{3}$. The B3LYP values of barrier heights are closer to experiment and accurate theory than the MP2 values.

b. While the B3LYP method predicts that concerted thermal decomposition of $\mathrm{MeN}_{3}, \mathrm{EtN}_{3}$ and $\operatorname{Pr}^{\mathrm{i}} \mathrm{N}_{3}$ to their respective singlet nitrenes is possible, this is ruled out by the MP2 results which instead predicts that these azides would undergo concerted 1,2 hydride shift with $\mathrm{N}_{2}$ elimination to yield alkanimines.

c. Insertion of the singlet nitrenes $\mathrm{HN}, \mathrm{MeN}$ and $\mathrm{AcN}$ into the four alkene substrates to yield aziridines is predicted by the B3LYP method as possible through a concerted and highly exothermic step. $\mathrm{HN}$ insertion in all these cases occurs without a barrier, while barriers for $\mathrm{AcN}$ insertion are lower than those for $\mathrm{MeN}$ insertion.

d. Addition of the triplet nitrenes $\mathrm{HN}, \mathrm{MeN}$ and $\mathrm{AcN}$ to the four alkene substrates forms a triplet diradical intermediate which undergoes ISC and collapse to yield the singlet aziridine, since the singlet diradical intermediate is not predicted to be a minimum. Formation of the triplet intermediate is exothermic with modest activation barriers which fall in the order of magnitude $\mathrm{MeN}$ $>\mathrm{HN}>\mathrm{AcN}$.

e. Transition states for the various steps studied here are labeled as "early" or "late" on the basis of their geometries which in turn is in good accordance with Hammond's postulate concerning relative position 
of transition states along the reaction coordinate for endothermic and exothermic reactions.

f. This B3LYP study has dealt with more azide reactants and alkene substrates than any previous computational study, often qualitatively agreeing with and extending many earlier findings. These B3LYP results differ from some (not all) higher level theoretical findings with regard to the existence as minima of alkylnitrenes having an $\alpha$-hydrogen.

\section{Supplementary Information}

Optimized geometries (in Cartesian coordinates) of the molecules studied here are given in the Supplementary Information which is available at www.ias.ac.in/ chemsci.

\section{Acknowledgments}

The authors thank the Council of Scientific and Industrial Research, Govt. of India, for computational facilities received through a sponsored research project. S.P.D. thanks the University Grants Commission, New Delhi, for financial assistance through the UGC Research Fellowship for Meritorious Students.

\section{References}

1. Breslow D S 1970 In Nitrenes (New York: Wiley Interscience)

2. Abramovitch R A 1973 In Organic Reactive Intermediates S P McManus (Ed.) (New York: Academic Press) p.127

3. Lwowski W 1984 In Azides and Nitrenes (New York: Academic Press)

4. Lwowski W 1984 In Azides and Nitrenes: Reactivity and Utility E F V Scriven (Ed.) (Orlando: Academic Press) p. 205

5. Moss R A, Platz M S, Jones Jr. M 2004 (Eds.) Reactive Intermediate Chemistry (New York: John Wiley)

6. Platz M S 2005 In Reactive Intermediate Chemistry (Hoboken: John Wiley)

7. Scriven E F V and Turnbull C K 1988 Chem. Rev. 88297

8. Jain S L and Sain B 2003 Tetrahedron Lett. 44575

9. Ando T, Kano D, Minakata S, Ryu I and Komatsu M 1998 Tetrahedron 541348

10. Vyas R, Chanda B M and Bedekar A V 1998 Tetrahedron Lett. 394715

11. Vyas R, Chanda B M, Belhekar A A, Patel D R, Ram R N and Bedekar A V 2000 J. Mol. Catal. 160237

12. Chanda B M, Vyas R and Bedekar A V 2001 J. Org. Chem. 6630

13. Oliva C G, Jagerovic N, Goya P, Alkorta I, Elguero J, Cuberes R and Dordalb A 2010 ARKIVOC 2127

14. Wirth T 2005 Angew. Chem. Int. Ed. 443656

15. Evans D A, Faul M M and Bilodeau M T 1991 J. Org. Chem. 566744

16. Evans D A, Faul M M and Bilodeau M T 1994 J. Am. Chem. Soc. 1162742
17. Prato M, Chan Li Q, Wudl F and Lucchini V 1993 J. Am. Chem. Soc. 1151148

18. Bellavia-Lund C and Wudl F 1997 J. Am. Chem. Soc. 119943

19. Averdung J, Luftmann H, Mattay J, Claus K and Abraham, W 1995 Tetrahedron Lett. 362957

20. Cases M, Duran M, Mestres J, Martın N and Sola M 2001 J. Org. Chem. 66433

21. Labbe G 1969 Chem. Rev. 69345

22. Abramovitch R A and Knaus N 1975 J. Org. Chem. 40 883

23. Hayashi Y and Swern D 1973 J. Am. Chem. Soc. 95 5205

24. Konars R S, Matsumoto S and Darwent B D 1971 Trans. Faraday. Soc. 671698

25. Eibler E and Sauer J 1974 Tetrahedron Lett. 382569

26. Inagaki M, Shingaki T and Nagai T 1982 Chem. Lett. 11 9

27. Lewis F D and Saunders W H 1968 J. Am. Chem. Soc. 1043828

28. Burdzinski G, Hackett J C, Wang J, Gustafson T L, Hadad C M and Platz M S 2006 J. Am. Chem. Soc. 128 3402

29. Richardson W C and Setser D W 1969 Can. J. Chem. 47 2725

30. Kajimoto O, Yamamoto T and Fueno T 1979 J. Phy. Chem. 83429

31. Bock H and Dammel R 1988 J. Am. Chem. Soc. 110 5261

32. O'Dell M S and Darwent B D 1970 Can. J. Chem. 48 1140

33. Alexander M H, Dagdigian P J and Werner H J 1991 Chem. Soc. 91319

34. Nguyen M T and Sengupta D 1999 J. Am. Chem. Soc. 1006499

35. Arenas J F, Marcos J I, Otero J C and Galvez A S 1999 J. Chem. Phys. 111551

36. Arenas J F, Otero J C, Sanchezgalvez A, Soto J and Viruela P 1998 J. Phys. Chem. 1021146

37. Arenas J F, Marcos J I, López-Tocón I, Otero J C and Soto J 2000 J. Chem. Phys. 1132282

38. Arenas J F, Marcos J I, Otero J C, Tocon I L and Soto J 2001 Int. J. Quantum Chem. 84241

39. Rafie H, Eittah A, Mohamed A A and Alomar A M 2006 Int. J. Quantum Chem. 106863

40. Luis A R, Xiaoqing Z, Sonia E U, Helmut B, Helge W and Carlos O D V 2012 J. Org. Chem. 776456

41. Darío J R D, Margarida S M and Joaquim C G E da S 2014 J. Phys. Chem. A 1185038

42. Abramovitch R A, Challand S R and Yamada Y 1975 J. Org. Chem. 401541

43. Indranirekha S, Bishwapran K and Prodeep P 2011 Chem. Commun. 472967

44. Horner L and Christmann A 1963 Angew. Chem. Int. Ed. Engl. 2599

45. Tisue G T, Linke S and Lwowski W 1967 J. Am. Chem. Soc. 896303

46. Isomura K, Ayabe G I, Hatano S and Taniguchi H 1980 J. Chem. Soc. Chem. Comm.

47. Anastassiou A G 1967 J. Am. Chem. Soc. 893184

48. McConaghy J S and Lwowski W $1967 \mathrm{~J}$. Am. Chem. Soc. 892357 
49. Lwowski W and Maricich J T 1965 J. Am. Chem. Soc. 873630

50. Cornell D W, Berry R S and Lwowski W $1966 \mathrm{~J}$. Am. Chem. Soc. $\mathbf{8 8} 544$

51. Lwowski W and Mattingly T W 1965 J. Am. Chem. Soc. 871947

52. Xiaoqing Z, Helmut B, Helge W, Patrik N, Dirk G and Wolfram S 2015 J. Phys. Chem. A 1192281

53. Gritsan N P, Platz M S and Borden W T 2005 Mol. Supramol. Photochem. 13235

54. Fueno T, Bona-Kouteckji V and Kouteckji J 1983 J. Am. Chem. Soc. 1055549

55. Haines W J and Czismadia I G 1973 Theor. Chim. Acta 31233

56. Yarkony D R, Schaefer H F and Rothenberg 1974 J. Am. Chem. Soc. 965974

57. Demuynck J, Fox D J, Yamaguchi Y and Schaefer H F 1980 J. Am. Chem. Soc. 1026204

58. Richards C, Meredith C, Kim, Quelch G E and Schaefer H F 1994 J. Chem. Phys. 100481

59. Kemnitz C R, Ellison G B, Karney W L and Borden W T 2000 J. Am. Chem. Soc. 1221098

60. Alewood P F, Kazmaier P M and Rauk A 1973 J. Am. Chem. Soc. 955466

61. Pritchina E A, Gritsan N P and Bally T 2005 Russ. Chem. Bull., Int. Ed. 541

62. Liu J, Mandel S, Hadad C M and Platz M S 2004 J. Org. Chem. 698583

63. Hammond G S 1955 J. Am. Chem. Soc. 77334

64. Becke A D 1993 J. Chem. Phys. 981372
65. Lee C, Yang W and Parr R G 1988 Phys. Rev. B 37785

66. Scott A P and Radom L 1996 J. Phy. Chem. 10016502

67. Merrick J P, Moran D and Radom L 2007 J. Phys. Chem. A 11111683

68. Frisch M J, Trucks G W, Schlegel H B, Scuseria G E, Robb M A, Cheeseman J R, Scalmani G, Barone V, Mennucci B, Petersson G A, Nakatsuji H, Caricato M, Li X, Hratchian H P, Izmaylov A F, Bloino J, Zheng G, Sonnenberg J L, Hada M, Ehara M, Toyota K, Fukuda R, Hasegawa J, Ishida M, Nakajima T, Honda Y, Kitao O, Nakai H, Vreven T, Montgomery Jr J A, Peralta J E, Ogliaro F, Bearpark M, Heyd J J, Brothers E, Kudin K N, Staroverov V N, Kobayashi R, Normand J, Raghavachari K, Rendell A, Burant J C, Iyengar S S, Tomasi J, Cossi M, Rega N, Millam J M, Klene M, Knox J E, Cross J B, Bakken V, Adamo C, Jaramillo J, Gomperts R, Stratmann R E, Yazyev O, Austin A J, Cammi R, Pomelli C, Ochterski J W, Martin R L, Morokuma K, Zakrzewski V G, Voth G A, Salvador P, Dannenberg J J, Dapprich S, Daniels A D, Farkas O, Foresman J B, Ortiz J V, Cioslowski

69. Geiseler V G and König W 1964 Z. Phys. Chem. (Leipzig) 22781

70. Gritsan N P and Platz M S 2006 Chem. Rev. 1063844

71. Dkhar P G S and Lyngdoh R H D 2005 J. Mol. Struct. (THEOCHEM) 732161

72. Kim S J, Hamilton T P and Schaefer H F 1992 J. Am. Chem. Soc. 1145349

73. Zaslonko I S, Kogarko S M and Mozzhukin E V 1976 Combust. Explos. Shock Waves 122 